\title{
The origin recognition complex: from simple origins to complex functions
}

\author{
Stephen P. Bell ${ }^{1}$ \\ Howard Hughes Medical Institute, Department of Biology, Massachusetts Institute of Technology, Cambridge, \\ Massachusetts 02139, USA
}

Eukaryotic DNA replication is an intricate process that requires the coordinate and tightly regulated action of numerous molecular machines. Eukaryotic cells must choose hundreds if not thousands of origins of replication and assemble multiple proteins or protein complexes at these sites. During $S$ phase, these complexes are activated in a reproducible, temporal program to generate twice this number of replication fork machines dedicated to DNA synthesis. Moreover, these machines must overcome the highly packaged nature of the eukaryotic genome to access all DNA sites, without exception.

The key factor in the selection of initiation sites and the assembly of the replication machinery is the initiator protein. Originally proposed by Brenner, Cuzin, and Jacob based on genetic findings, the replicon model hypothesized the existence of two essential components required for replication initiation: the initiator and the replicator (Jacob et al. 1963). The initiator is a positively acting factor that recognizes a specific DNA sequence within the genetic element required for initiation, called the replicator. The replicator usually overlaps the site of replication initiation, the origin of replication. Subsequent studies in Escherichia coli, other bacteria, and many bacteriophages and eukaryotic viruses identified initiator proteins and confirmed this basic model. Unlike these organisms, each of which uses a single replicator to duplicate their genome, eukaryotic chromosomes each require multiple replicators to ensure complete replication of their genome in a timely manner. Although it was possible that multiple initiators functioned in this more complex situation, studies over the last 10 years have demonstrated that a single conserved eukaryotic initiator directs all of these initiation events: the origin recognition complex (ORC).

The well-defined replicators of Saccharomyces cerevisiae provided the critical tools to identify ORC. These sequences were originally identified by their ability to confer stable propagation to yeast episomes and were called autonomous replicating sequences (ARSs). Subsequent studies provided definitive evidence that these

${ }^{1}$ E-MAIL spbell@mit.edu; FAX (617) 253-4043.

Article and publication are at http://www.genesdev.org/cgi/doi/10.1101/ gad.969602. sites represented true chromosomal replicators and overlapped with their associated origins of replication (for review, see Bell 1995). Mutational analyses of ARS elements identified an essential, conserved, 11-bp element associated with all ARS elements known as the ARS consensus sequence (ACS or "A element"), as well as multiple 10-15-bp "B-elements" that also contribute to origin function. The conserved nature of the ACS made it a likely target for a eukaryotic initiator and many efforts were made to identify such a factor. ORC was ultimately identified based on its affinity for the ACS and was therefore a strong candidate for the eukaryotic initiator (Bell and Stillman 1992). DNA binding by this sixprotein complex (referred to as Orc1p-Orc6p, from largest to smallest subunit) requires ATP (see below), and it is likely that this requirement as well as the low-abundance of ORC thwarted previous attempts to identify this factor.

Abundant evidence now supports the conclusion that ORC is the $S$. cerevisiae initiator. Point mutations in the ACS that eliminate ORC binding in vitro and in vivo also result in loss of replicator activity supporting the hypothesis that ORC mediates the function of this critical element (Bell and Stillman 1992; Li and Herskowitz 1993; Aparicio et al. 1997; Tanaka et al. 1997). Mutations in the genes encoding the subunits of the ORC complex result in DNA replication defects and prevent the association of all other replication factors at the origin (Bell et al. 1993; Foss et al. 1993; Micklem et al. 1993; Santocanale and Diffley 1996; Dillin and Rine 1997, 1998). Finally, in vivo footprinting, protein-DNA cross-linking, and chromatin precipitation studies all indicate that ORC is bound to $S$. cerevisiae origins of replication throughout most if not all of the cell cycle (Diffley et al. 1994; Aparicio et al. 1997; Liang and Stillman 1997; Tanaka et al. 1997).

Unlike the simple replicators of $S$. cerevisiae, replicators in other eukaryotic organisms remain poorly defined (for review, see Bielinsky and Gerbi 2001; Gilbert 2001). The most obvious difference between replicators in $S$. cerevisiae and other organisms is at the level of size. Even in the single cell eukaryote, Schizosaccharomyces pombe, replicators are found to be 5- to 10-fold larger than their $S$. cerevisiae counterparts. Replicators derived from multicellular eukaryotes are still less well defined 
and only a few have been mapped in any detail. In multicellular organisms the number and location of origins are regulated during development. Particularly dramatic examples of such changes in origin usage are observed during development of Drosophila melanogaster and Xenopus laevis. The rapid DNA replication observed in the early embryos of these species is mediated by tens of thousands of origins spaced by as little as 4-7 kb (Blumenthal et al. 1974). Later in development, inter-origin distances increase, reducing the number of replicators used by $\geq 10$-fold (Hyrien et al. 1995; Sasaki et al. 1999). Interestingly, in vitro experiments using Xenopus egg extracts indicate that there is little or no sequence specificity required for the initiation of DNA replication (Coverley and Laskey 1994). Indeed, although numerous studies have pursued the identification of essential elements within other replicators, as of yet, no element with similar properties to the $S$. cerevisiae ACS has been identified in any other eukaryote.

Despite differences in their structure and a lack of obvious conserved sequences among eukaryotic replicators, ORC is a conserved feature of replication initiation in all eukaryotes tested. ORC-related genes have been identified in organisms ranging from $S$. pombe to plants to humans (for review, see Dutta and Bell 1997). Mutational analysis of ORC-related genes in $S$. pombe and $D$. melanogaster both reveal defects in DNA replication (Muzi-Falconi and Kelly 1995; Grallert and Nurse 1996; Landis et al. 1997; Pinto et al. 1999; Loupart et al. 2000; Pflumm and Botchan 2001). Similarly, immunodepletion studies using $X$. laevis replication competent extracts indicate an absolute requirement for ORC to initiate DNA replication (Carpenter et al. 1996; Romanowski et al. 1996; Rowles et al. 1996). Although no genetic evidence indicates that ORC functions in human chromosomal DNA replication, plasmids replicating in human cells by virtue of an Epstein Barr Virus (EBV) replicator are defective in cells carrying an ORC2 mutation (Dhar et al. 2001b). This, together with other evidence, indicates that EBV uses the human replication initiation machinery, and suggests that HsORC functions in human DNA replication. Thus, even in multicellular organisms that have yet to show evidence of conserved sequences required for replication initiation, ORC has been retained as an essential component of the replication initiation process.

In all cases studied, ORC binding to the replicator is the first step in the establishment of a multifactor assembly called the prereplicative complex (pre-RC, for review, see Bell and Dutta 2002). After ORC binds DNA, it recruits several additional DNA replication factors including Cdc6p, Cdt1p, and the Mcm2-7p complex (MCM complex) to the origin. Pre-RC assembly is initiated at the $M / G_{1}$ transition of the cell cycle and, once established, the pre-RC is maintained during $\mathrm{G}_{1}$. On entry into $S$ phase, existing pre-RCs are activated in a characteristic temporal pattern as cells progress through $S$ phase. Both cyclin-dependent kinases (CDKs) and the Dbf4p-dependent kinase (DDK, whose catalytic subunit is $C d c 7 p$ ) are required to trigger initiation, although the exact targets and consequences of these modifications remain unclear. In addition to activating existing pre$\mathrm{RCs}$, the elevation of CDK activity also plays a key role in preventing new pre-RC formation until the following $S$ phase (for review, see Bell and Dutta 2002). In this review, I will discuss first what we know about the role of ORC in each of these events. Then, I will describe studies addressing other roles for ORC in the cell. When relevant, ORC derived from different organisms will be distinguished using the initials of the genus and species names preceding ORC (e.g., SpORC is $S$. pombe ORC).

\section{ORC and origin specification}

Studies of ORC across a wide range of eukaryotic species indicate that localization of this complex is the initial step in determining the sites of DNA replication initiation. Despite this, the mechanism by which ORC is localized to origins of replication remains incompletely understood. In S. cerevisiae, the ACS and B1 elements play a large part in directing ORC to origins of replication, however, these sequences are unlikely to be sufficient to direct ORC localization independently. In other eukaryotes, sequences that direct ORC binding are unknown. Indeed, in some cases there appears to be little or no DNA sequence selectivity for the location of origins.

\section{DNA binding by ScORC}

The most well characterized activity of ORC is its ability to bind origin DNA. Although initial studies identified the ACS as the S. cerevisiae ORC (ScORC) binding site (Bell and Stillman 1992), further studies demonstrated that there was at least one additional interaction within the adjacent B1 domain (Rao and Stillman 1995; Rowley et al. 1995). Detailed studies of the contacts between ORC and origin DNA support an extensive interaction between ScORC and the origin and identify additional sequences that interact with ORC between the A and B1 region (Lee and Bell 1997). Interestingly, these studies also found that ORC primarily interacts with the A-rich strand of the ACS, suggesting that other replication factors can gain access to the opposite strand of the ACS without displacing ORC.

The interaction of ORC with origin DNA involves multiple subunits. Protein-DNA cross-linking studies indicate that four of the six ScORC subunits (Orclp, Orc2p, Orc4p, and Orc5p) form close contacts with the origin DNA (Fig. 1A; Lee and Bell 1997). Although ScOrc3p does not cross-link to origin DNA, this subunit is required for ScORC to bind origin DNA, suggesting an involvement in positioning the other ORC subunits for appropriate interaction with the origin. Only ScOrc6p is dispensable for sequence-specific DNA binding by ScORC, although it is still required for ORC function in vivo (Lee and Bell 1997). In contrast, studies of Drosophila ORC indicate that all six ORC subunits are required for efficient DNA binding as well as for in vitro DNA replication (Fig. 1C; Chesnokov et al. 2001). 


\section{S. cerevisiae}

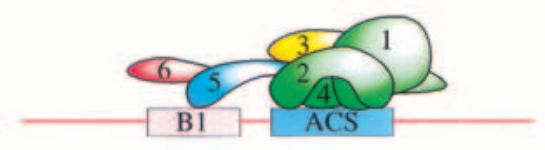

S. pombe

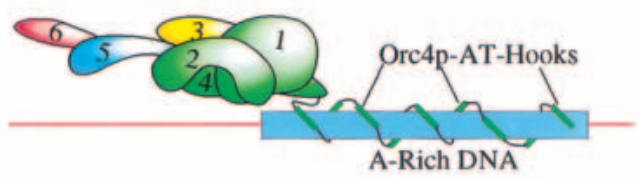

\section{D. melanogaster}

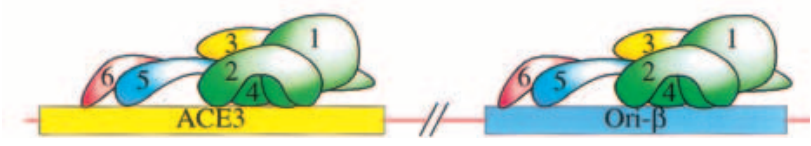

Figure 1. Association of origin recognition complex (ORC) with known replicators. The association of ORC with Saccharomyces cerevisiae origins involves four of the six subunits (Orc1p, Orc2p, Orc4p, and Orc5p) recognizing the 11-bp autonomous replicating sequence (ARS) consensus sequence (ACS) as well as several less well-defined adjacent DNA sequences including a subset of B1 element sequences. Binding of Schizosaccharomyces pombe ORC (SpORC) to its cognate origins involves a clearly distinct mechanism involving nine repeats of an AT-hook motif found uniquely at the $\mathrm{N}$-terminus of the $S$. pombe Orc4 subunit. A discrete binding site has not been identified, however recent studies indicate that SpORC recognizes stretches of A-rich DNA. Less is known about the sequences recognized by Drosophila ORC (DmORC), however, ATP-dependent binding to both the ACE3 and ori- $\beta$ elements of the third chromosome have been detected in vivo and in vitro. Unlike ScORC, all six subunits of DmORC are required for DNA binding. See text for additional details and references.

The complex nature of the ORC-DNA interface has interfered with a precise determination of the DNA binding motifs involved in origin recognition. With one exception (see below), sequence comparison has not identified any clear DNA binding motifs in any ORC subunit from any species. The determination of the crystal structure of an archaeal Cdc6p/Orclp-related protein has revealed a candidate DNA binding domain (Liu et al. 2000). Analysis of this structure revealed a region of the $\mathrm{C}$-terminus of the archaeal protein that forms a fold related to the winged-helix DNA binding domain. More importantly, this region is conserved in both Cdc6p and Orclp derived from multiple species, raising the interesting possibility that this region of Orclp mediates, at least in part, DNA binding by ORC.

Recent work has taken advantage of the ability to cross-link ORC to its binding sites in vivo to identify ORC binding sites across the $S$. cerevisiae genome (Wyrick et al. 2001). This study used the chromatin immunoprecipitation (ChIP) technique to isolate DNA fragments cross-linked to ORC and applied the isolated
DNA to DNA microarrays to identify the associated DNAs. Approximately 460 ORC binding sites were identified in $G_{2} / M$ arrested cells (cells arrested at $G_{2} / M$ were chosen due to the occlusion of ORC in $\mathrm{G}_{1}$ cells by other members of the pre-RC, making detection of ORC by ChIP difficult; Aparicio et al. 1997). Of these binding sites, a majority are within intergenic regions and $>90 \%$ are in close proximity to the binding sites of the MCM proteins during $G_{1}$, suggesting that they direct the formation of pre-RCs. By combining the information of ORC and MCM localization with the sites of known origins of replication, an algorithm was developed to predict sites of potential origins. Using this algorithm, 429 proposed ARSs were predicted. When a subset of these sites were tested directly, $\sim 80 \%$ acted as ARS elements in plasmids. In addition, 13 of 15 sites predicted to act as origins on $S$. cerevisiae chromosome $\mathrm{X}$ by an alternative whole genome analysis of replication intermediates were included in this set (Raghuraman et al. 2001). Although not a perfect predictor of origin activity, this approach shows a robust ability to delimit the sites of possible origins to within $<1 \mathrm{~kb}$. When combined with other methods to confirm the sites of replication initiation, this method has the potential to greatly increase the number of identified origins in other eukaryotes. It is interesting to note that there appear to be more predicted ORC binding sites than origins, suggesting that a subset of the these sites are involved in other cellular functions (see below). In addition, ORC does not interact strongly with inefficient origins in $\mathrm{G}_{2} / \mathrm{M}$ arrested cells, although it is likely that other factors stimulate ORC binding to these sites during $\mathrm{G}_{1}$ (see below; Wyrick et al. 2001).

\section{Can ORC bind specific sequences in other eukaryotes?}

Although a consensus ORC binding site has not been identified other than the $S$. cerevisiae ACS, studies in several other organisms are consistent with ORC recognizing DNA sequences within known replicators in vivo. ChIP experiments using $S$. pombe cells have demonstrated that ORC is associated with multiple origins in vivo (Ogawa et al. 1999). In situ analysis of DmORC using mitotic and polytene chromosomes shows a staining pattern consistent with a defined pattern of DmORC localization along the chromosomes (Pak et al. 1997). ChIP experiments confirm the association of DmORC with elements of the well-characterized ACE3 origin of DNA amplification. These studies also suggest that DmORC interacts with multiple sequences adjacent to $A C E 3$ in a manner that does not appear to be highly sequence specific but nonetheless requires proximal ACE3 DNA (Austin et al. 1999). The specificity and biological relevance of these additional interactions remains unclear. Similar cross-linking studies indicate human ORC (HsORC) associates with the EBV origin of replication, although association with this site appears to be mediated by the viral DNA binding factor, EBNA1 (Chaudhuri et al. 2001; Dhar et al. 2001b; Schepers et al. 2001).

Unlike other ORC analogs, SpORC includes at least 
one clear DNA binding motif (Fig. 1B). Cloning of the gene encoding SpOrc4p, revealed that this subunit of SpORC contains nine repeats of an AT-hook motif not present in the Orc4 subunits derived from other species (Chuang and Kelly 1999). This motif was previously identified as a DNA binding domain in HMG proteins that recognizes AT-rich tracts of DNA (Reeves and Beckerbauer 2001). Interestingly, studies of other AT-hook proteins suggest that they can recognize or induce structural changes in bound DNA. In vitro binding experiments indicate that the SpOrc4p can interact with both the ars3002 and ars1 origins of replication (Chuang and Kelly 1999; Kong and DePamphilis 2001; Lee et al. 2001). DNase I footprinting identified several specific AT-rich binding sites within these origins, most of which included regions of poly $(\mathrm{A})$ ( $\geq 5$ consecutive A residues; Kong and DePamphilis 2001; Lee et al. 2001). Such binding is not simply association with AT-rich DNA because other sequences that included stretches of poly(AT) were not bound. Interestingly, although the remaining five subunits of SpORC were able to interact with SpOrc4p bound to DNA, they did not appear to have any sequence-specific DNA binding activity on their own, nor did they alter the interaction of prebound SpOrc4p with the origin DNA (Kong and DePamphilis 2001; Lee et al. 2001). These findings demonstrate that SpOrc4p is a sequence-specific DNA binding protein and indicate that SpOrc $4 p$ is largely responsible for the sequence specificity of SpORC.

Studies of metazoan ORCs have been less clear concerning specific ORC binding sites. Studies of replication in embryonically derived extracts indicate that virtually any sequence can be replicated (for review, see Coverley and Laskey 1994). Despite this apparent lack of specificity, studies of Xenopus egg extracts indicate that XlORC is limiting for DNA replication and saturates added DNA at approximately one ORC molecule per $16 \mathrm{~kb}$ (Rowles et al. 1999; Blow et al. 2001). Saturation could be attributable to a limited number of specific DNA binding sites, limited access to DNA, or stabilization of a subset of bound ORC molecules by other replication or chromatin factors.

Of the ORCs derived from multicellular organisms, only DmORC has been extensively studied in direct DNA binding experiments (Fig. 1C). Gel shift assays using DmORC purified from early embryos found a clear preference for binding to critical elements of the Drosophila chorion amplification loci $(A C E 3$ and ori- $\beta / A E R$ d) but significantly lower affinity for two adjacent sequences with the same AT-content (Austin et al. 1999). Recombinant DmORC also binds ori- $\beta$ and ACE3 but this affinity is not reported to be any higher than to equally AT-rich sequences such as the ends of P-elements (Chesnokov et al. 1999, 2001), suggesting that there may be differences in the specificity of extractderived and recombinant DmORC. Interestingly, the same recombinant DmORC specifically binds the amplification origin II/9A of the fly, Sciara coprophila at a sequence near the site of initial nucleotide incorporation (Bielinsky et al. 2001). This same region is also associ- ated with Sciara ORC in vivo. Despite the differences in the degree of specificity in these reports, in all cases sequence-specific DNA binding by DmORC is ATP-dependent. Overall, these studies suggest that ORC from metazoans retains DNA sequence specificity but apparently not at the level observed for ORC derived from $S$. cerevisiae.

It is important to note that although no distinct binding site for ORC has been identified in organisms other than $S$. cerevisiae, this may be attributable to a lack of tools to identify such a site. Only recently has ORC been purified from species other than S. cerevisiae and few studies of the DNA binding properties of these complexes, either in vivo or in vitro, have been performed. Interestingly, for the two species in which such studies have been performed ( $S$. pombe and Drosophila) there is clear evidence for specific DNA binding activity. In addition, the lack of robust assays to identify critical sequences within metazoan origins has hampered the identification of potential ORC binding sites.

Beyond DNA sequence specificity: helping ORC to the origin

Even in S. cerevisiae it is unlikely that the sequence specificity of ORC is sufficient for localization to origin sequences. Searching for matches to the ACS in the yeast genome indicates that this consensus alone is not sufficient to identify an ORC binding site or an origin (Newlon and Theis 1993; Wyrick et al. 2001). Mapping of ScORC binding sites across the yeast genome supports a hypothesis that there are other factors that facilitate ScORC localization. These studies find that strong ScORC binding sites are distributed throughout the genome with an average spacing of $\sim 20-30 \mathrm{~kb}$ (Wyrick et al. 2001). However, in vitro DNA binding experiments suggest that ScORC does not have the intrinsic DNA binding specificity required to recognize a single sequence every 20-30-kb region (R.D. Klemm, J.R. Lipford, and S.P. Bell, unpubl.).

If ORC does not have the ability to select origins based solely on its own affinity for specific DNA sequences, then how does it become localized across the genome? There are three general types of mechanisms that could be involved (Fig. 2). First, the association of other replication factors with ORC could enhance its interaction with appropriate sequences (Fig. 2A). Second, other factors that interact specifically with DNA could be involved in recruiting ORC to specific sites in the genome (Fig. 2B). Third, attributes of chromatin structure in specific regions of the genome could restrict or delineate areas that ORC can function (Fig. 2C). There is evidence consistent with each of these possibilities.

Studies of the interaction of ORC with origin DNA in the presence of other pre-RC components suggest that these factors may contribute to the specificity of ORC localization (Fig. 2A). One candidate to increase the specificity of ORC association with DNA is Cdc6p. Studies of the association between ScORC and ScCdc6p indicate that it is facilitated by origin DNA (Mizushima 


\section{A. Stabilized DNA Binding}

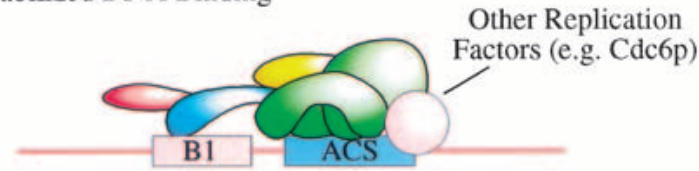

B. Recruitment

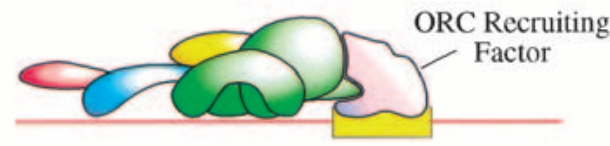

C. Local Chromatin Structure

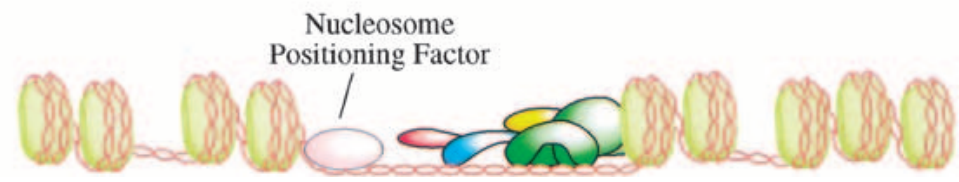

Figure 2. Potential mechanism controlling origin recognition complex (ORC) localization. Several possible mechanisms are likely to contribute to the specification of ORC chromosomal binding sites. (A) In Saccharomyces cerevisiae cells, a key component of localization is the recognition of specific sequences within the replicator. Additional replication factors (e.g., Cdc6p), however, may augment ORC DNA binding. (B) Studies of Drosophila and Epstein Barr Virus replication suggest distinct, sequence-specific DNA binding factors direct ORC localization through proteinprotein interactions. $(C)$ The localization of origins to intergenic regions suggests that local chromatin structure or the negative action of transcription may serve to restrict and/or facilitate ORC localization. Other mechanisms that would fall into this class would be displacement by RNA polymerase, modification of DNA, and modification of histones. See text for details and references. et al. 2000). Moreover, the interaction between ORC and Cdc6p reduced the off-rate of ORC from origin but not from nonorigin fragments. Although the mechanism responsible for the reduced off-rate is unclear, it required an intact Cdc6p ATP-binding motif. In addition, the interaction between ORC and Cdc6p appeared to alter the conformation of one or more ORC subunits and this change could lead to enhanced interaction with the origin (Mizushima et al. 2000).

A role for sequence-specific DNA binding factors in the recruitment of ORC to specific genomic loci has been suggested by studies of the Drosophila ACE3 amplification origin (Fig. 2B). The Drosophila analogs of the E2F1 transcription factor (dE2F1) and Rb (Rbf) are associated with a subset of ORC in Drosophila cells (Bosco et al. 2001). More importantly, mutant alleles of dE2F1, Rbf, and the Drosophila Dp analog each have strong effects on the localization of ORC and the function of the ACE3 amplification origin (Royzman et al. 1999; Bosco et al. 2001). Studies of the association of HsORC with the EBV origin of replication suggest that the viral transcription factor EBNA1 could play a similar role in the recruitment of ORC to these sites (Chaudhuri et al. 2001; Dhar et al. 2001b; Schepers et al. 2001). It is interesting to note that, if such a mechanism does operate in eukaryotic cells, then it is likely that a number of different DNA binding factors would be involved in recruiting ORC. Otherwise, origins would each contain a consensus-binding site for the ORC recruiting factor.

Other mechanisms that could influence ORC localization include local or global chromatin structure, DNA modification, or transcription itself. There is a strong tendency for origins and ORC binding sites to be located in intergenic regions (Brewer 1994; Gilbert 2001; Wyrick et al. 2001), raising the possibility that ORC could be displaced by elongating RNA polymerases. Studies in $S$. cerevisiae argue against such a mechanism, as origins and ORC binding sites appear restricted to intergenic regions even in poorly transcribed regions of the genome.
Alternatively, the open chromatin structure associated with the control regions of genes may provide increased access for ORC or other replication factors (Fig. 2C). Consistent with nucleosomes restricting possible sites of ORC localization, in vivo studies indicate that positioning a nucleosome over the ORC binding site at an origin inactivates origin function (Simpson 1990). More importantly, even subtle changes in the local chromatin structure can have a significant impact on origin usage, although this effect does not appear to be at the level of ORC DNA binding (Lipford and Bell 2001). Such a mechanism could explain the increased restriction of origin sites as embryonic cells begin transcription (Hyrien et al. 1995; Sasaki et al. 1999). Modification of DNA and/or histones also represents a likely mechanism to restrict the number of possible ORC binding sites. In this regard, it is interesting that human Orclp is found to associate with the Hbol histone acetyltransferase (Iizuka and Stillman 1999; Burke et al. 2001). Finally, although neither ORC binding sites nor origins of replication colocalize with sites of chromatid cohesion in $S$. cerevisiae (Blat and Kleckner 1999; Laloraya et al. 2000; Wyrick et al. 2001), it is possible that proteins involved in higher order packaging of the genome influence ORC localization either directly or indirectly.

It is likely that some composite between ORC DNA sequence specificity and these other methods to enhance or restrict ORC DNA binding will be at work in all organisms. Each organism is likely to balance this equation in a characteristic manner to accommodate different requirements for origin density and location. Indeed, it is likely that similar mechanisms are involved in the localization of other DNA binding factors in the cell. For example, it is possible that there are general methods used across eukaryotic genomes to prevent sequencespecific binding to transcribed regions. As an understanding of how ORC interacts with DNA emerges, it will be interesting to see if the elements involved in specific binding in $S$. cerevisiae are adapted for other 
DNA interactions in organisms showing less sequence specificity. Given the clear conservation of ORC and its architecture across eukaryotes, it is unlikely that all of the DNA interaction domains have been eliminated. Given that four of the six ORC subunits contact the DNA in ScORC, it is possible that one or more of these contacts are involved in interactions with the origin required for pre-RC formation or some other nonsequencespecific event. Consistent with this hypothesis, despite the apparently unique method of DNA binding for SpORC, the SpOrc1-5 subunits are still well conserved.

Regardless of the mechanism that is used to localize ORC and other factors to origins of replication, these proteins are clearly excellent markers for potential origins of replication. The development of technology to identify sites of DNA binding for ORC and other replication proteins across the genome will provide a powerful tool to map these loci in the future. Indeed, just as the conserved, simple origins of $S$. cerevisiae were critical to the identification of ORC, the identification of ORC and other origin-associated factors represents a key tool to identify and characterize their cognate origins/binding sites.

\section{Pre-RC assembly and the ATP regulation of ORC}

Once bound to origin DNA, ORC recruits the components of the pre-RC. This involves the interaction of ORC with at least two and possibly several other components of the preinitiation machinery. In addition, ORC remains at the origin throughout $G_{1}$ and $S$ phase, raising the possibility that ORC functions in events after pre-RC formation. Interestingly, recent studies suggest that these functions are unlikely to involve the recruitment of other replication factors. The identification of ORC as an ATPase has led to the hypothesis that its function in these events is regulated by nucleotide.

\section{$A T P$ regulation of $O R C$ function}

ORC generally requires ATP to interact specifically with origin DNA (the exception being SpORC) and in all species studied, Orc1p, Orc4p, and Orc5p, each contain potential ATP binding sites based on amino acid sequence analysis. Mutations in the ScOrclp and ScOrc5p ATP binding motifs both interfere with ScORC ATP binding (Klemm et al. 1997). Assessment of the consequences of making the same mutations in vivo found that a mutation in the ScOrclp ATP binding site was lethal whereas mutation of the ScOrc5p ATP binding motif had no obvious phenotype. Consistent with the lethal phenotype of the ScOrclp mutation, in vitro studies indicate that mutation of the ScOrc1p but not the ScOrc4p or ScOrc5p subunits interfere with DNA binding by ORC (Klemm et al. 1997). DmORC also requires ATP to bind tightly to DNA and includes ATP binding motifs in DmOrclp, 4p, and $5 \mathrm{p}$ (Chesnokov et al. 2001). Analysis of DmORC complexes mutated in these three motifs indicates that only mutations in the DmOrclp ATP binding motif in- terfere with DNA binding and ORC function in reconstituted DNA replication. Thus, despite the conservation of the Orc4p and Orc5p ATP binding motifs across multiple species, a requirement for these motifs for ORC function has yet to be established. It remains possible that ATP binding to these domains is required for nonessential ORC functions, such as DNA replication checkpoints or transcriptional silencing (see below).

ORC also hydrolyzes ATP (Klemm et al. 1997; Chesnokov et al. 2001). As with ATP control of DNA binding, studies of ATP hydrolysis by ORC have been performed for both DmORC and ScORC with similar findings. In both cases only mutations in the Orclp ATP binding motif interfere with ATP hydrolysis. Binding of ScORC to origin DNA inhibits ATP hydrolysis by 8 - to 10 -fold and a similar twofold inhibition by DNA is observed for DmORC. For ScORC, this effect requires the presence of the ACS. Origin DNA lacking an ORC binding site has little or no effect on ATP hydrolysis by ORC. Thus, Orclp is a central regulator of ORC function. Orclp directly interacts with origin DNA, binds the ATP required for ORC to recognize origin DNA, and alters its rate of ATP hydrolysis in response to origin binding.

Together these findings suggest a model in which, once ORC is bound to origin DNA, the bound ATP that is required for stable DNA binding is not immediately hydrolyzed. Instead, hydrolysis of this ATP is proposed to be conserved for a subsequent step in the replication process. There are several key issues that remain to be addressed regarding this model. Is ATP binding by ORC required for additional events beyond origin recognition? What event(s) triggers ATP hydrolysis by ORC? What are the consequences of ATP hydrolysis by ORC? Recent studies have shed some light on these questions.

In addition to binding double-stranded DNA (dsDNA) forms of the origin, ScORC also has a high affinity for single-stranded DNA (ssDNA, $\mathrm{K}_{\mathrm{d}} \approx 10^{-8}$; Lee et al. 2000). Unlike ScORC binding to dsDNA, ScORC's association with ssDNA is neither sequence-specific nor ATP-dependent. Instead, the affinity of ScORC for ssDNA is determined by the length of the ssDNA, with molecules greater than $\sim 80$ bases having the highest affinity. This association requires the same five subunits of ScORC required for dsDNA binding. Association with ssDNA alters ScORC function in two ways (Lee et al. 2000). First, it stimulates the rate of ATP hydrolysis $\sim 20$-fold relative to ORC bound to origin DNA. Second, electron microscopy analysis of ScORC function indicates that binding to ssDNA stabilizes an altered structure. Because ssDNA is a direct consequence of the initiation process, these observations suggest that the generation of ssDNA during initiation is coupled to activation of the ORC ATPase and alteration of its structure.

\section{$O R C$ recruitment of replication factors: $O R C$ as a landing pad}

Once bound to DNA, ORC plays a critical role in the recruitment of additional replication factors to the origin. Studies in S. cerevisiae, S. pombe, and Xenopus have 
all demonstrated that ORC is required for the recruitment of the known components of the pre-RC to the origin. The recruitment of these factors occurs in an ordered process: Cdc6p and Cdt1p load first followed by Mcm2-7p. As cells pass through the $G_{1}$ to $S$ phase transition additional replication factors are recruited to the origin. These factors include CDKs and DDK, Cdc45p, the three eukaryotic DNA polymerases, and the eukaryotic ssDNA binding protein, RPA (for review, see Bell and Dutta 2002). As with the components of the pre-RC, either cells or extracts lacking ORC fail to assemble these additional factors at the origin. Although it is clear that ORC is required to initiate the assembly of all of these factors at the origin, ORC has only been shown to interact directly with a small subset of these factors. Recent studies of replication in Xenopus extracts suggest that many of these factors do not require ORC bound to the origin at the time of assembly (Hua and Newport 1998; Rowles et al. 1999). The simplest interpretation of ORC's role in these events is that it acts as a "landing pad" to localize other factors to the site of initiation.

There is abundant evidence that ORC interacts directly with Cdc6p. In vitro studies have identified a direct interaction between ORC and Cdc6p that depends on binding of ORC to origin DNA (Mizushima et al. 2000). In human cells, HsOrclp and HsCdc6p coelute through multiple columns and can be shown to interact with one another directly in in vitro assays (Saha et al. 1998). This suggests the interesting possibility that these two factors dynamically associate with the remainder of HsORC in a coordinated fashion (see below). Interestingly, several lines of evidence support the hypothesis that this interaction is likely to require ATP-bound Orc1p. First, the requirement for origin DNA to observe the ORC-Cdc6p interaction described above is consistent with a requirement for ATP-bound ORC. Second, using a reconstituted assay for pre-RC formation, ATP was required for association of Cdc $6 \mathrm{p}$ with ORC and the origin (Seki and Diffley 2000). Third, studies of a dominant allele of ScORC1 that is defective in ATP hydrolysis suggest that the dominant effect is mediated by excess ATP-bound ORC titrating Cdc6p away from the origin (Klemm and Bell 2001). In addition to direct biochemical studies, genetic interactions between ORC and Cdc6p have also been observed including the ability of excess CDC6 expression to suppress the lethality of an Scorc5-1 allele (Liang et al. 1995).

Interaction of ORC with other replication factors is less well documented. Although it is likely that ORC will interact with Cdt1p and Mcm2-7p, evidence for these interactions is largely circumstantial. For example, studies of Xenopus replication extracts and $S$. pombe cells indicate that Cdc6p and Cdt1p independently load onto chromatin in an ORC-dependent manner (Maiorano et al. 2000; Nishitani et al. 2000). This would suggest a direct interaction between ORC and Cdt1. In addition, given the relative sizes of ORC and the MCM complex, these complexes are likely to interact during pre-RC formation. Studies of the nuclear localization and association of ScDbf4p (the regulatory subunit of
ScDDK) with chromatin also suggest a direct interaction with ORC (Pasero et al. 1999). Mutations in ScORC2 interfere with the formation of subnuclear ScDbf4p foci and the association of ScDbf4p with chromatin fractions. Interestingly, this association is independent of Cdc $6 \mathrm{p}$ and MCM loading suggesting that the requirement for ORC is direct and not attributable to ORC's role in pre$\mathrm{RC}$ formation. This interaction is also supported by onehybrid assays using the ACS as a target (Dowell et al. 1994). These studies identified ScDbf4p as a factor that associates with an ACS-recognizing complex. A more detailed understanding of the interaction between ORC and other pre-RC components will only be possible through the characterization of assays for pre-RC formation using purified proteins.

\section{The ORC ATPase at the origin: clamp loader or initiation detector}

The ATP-dependence of ORC's interaction with Cdc6p and potentially other replication factors suggests that hydrolysis of ATP by ORC could have significant consequences for the formation, activation, or disassembly of the pre-RC (Fig. 3). One intriguing possibility is suggested by the similarity between several ORC subunits (Orc1p, 4p, and 5p), Cdc6p, and the subunits of the eukaryotic and prokaryotic clamp loaders (RF-C and the $\gamma$ complex, respectively; Perkins and Diffley 1998). Studies of the clamp loading complexes indicate that they require binding to ATP to associate with and open the sliding clamp (e.g., PCNA). When the clamp loader associates with DNA, ATP hydrolysis is stimulated, causing the release of the sliding clamp such that it encircles the bound DNA (for review, see Ellison and Stillman 2001). A similar mechanism could be used by ORC and/ or Cdc6p to assemble the ring-shaped MCM complex onto the origin during pre-RC formation (Fig. 3A; Adachi et al. 1997; Perkins and Diffley 1998). Consistent with this hypothesis, studies of an in vitro pre-RC assembly reaction indicate that ATP hydrolysis is required to assemble the MCM proteins onto the origin (Seki and Diffley 2000). Determining the proteins responsible for this ATPase activity is difficult due to the multiple ATPases involved in pre-RC formation. ORC, Cdc6p, and the MCM proteins are each known to hydrolyze ATP and it remains possible that there are other unknown ATPases involved in pre-RC formation. If the MCM proteins are loaded around the DNA during pre-RC formation they are most likely placed around a double stranded form of the origin. Studies of pre-RC complexes have found no evidence for the formation of unwound DNA /Geraghty et al. 2000; Walter and Newport 2000). Assuming that the MCM proteins act as the replicative DNA helicase (for review, see Labib and Diffley 2001), encircling dsDNA would be unusual as replicative DNA helicases are typically found to encircle ssDNA (e.g., see O'Donnell and Hingorani 2000 and references therein).

An alternative role for ATP hydrolysis by ORC is suggested by the ability of ssDNA to stimulate the ORC ATPase (Fig. 3B). It is possible that the formation of 
A

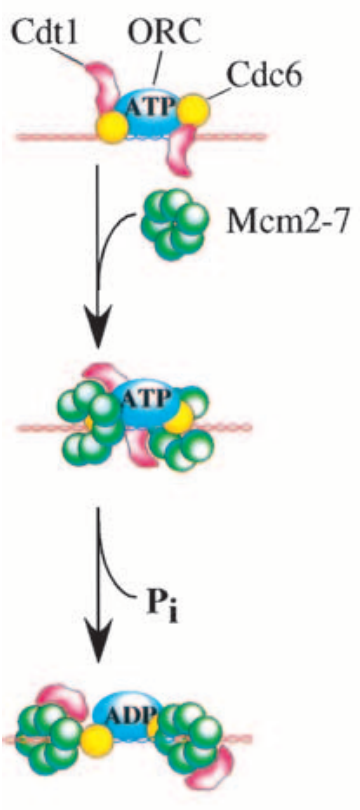

B
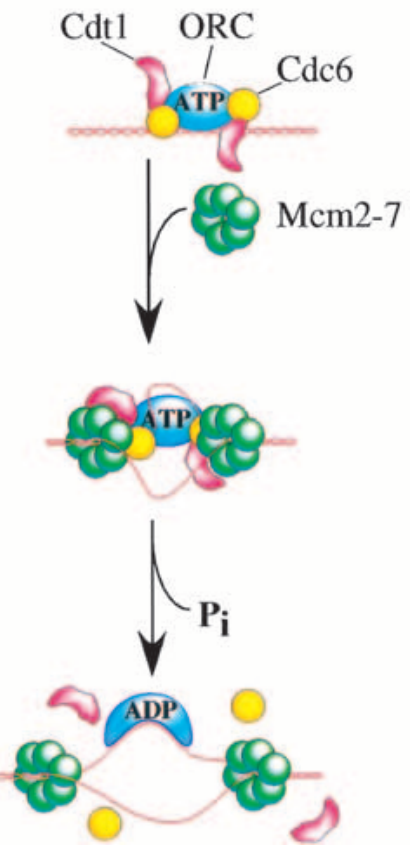

Figure 3. Two models for the ATP regulation of origin recognition complex (ORC). (A) Clamp loader. The similarity of ORC and Cdc $6 \mathrm{p}$ to subunits of the RF-C and $\gamma$-complex clamp loaders has led to the suggestion that ORC/Cdc6p may act as a clamp loader for the ring shaped Mcm2-7p complex (MCM complex) during pre-RC formation. If so, it is likely that ORC/Cdc6p ATP binding is coupled to ring-opening of the MCM complex and that ATP hydrolysis is coupled to release and closure of the MCM complex ring around double-stranded DNA. (B) Initiation to elongation switch. An alternative hypothesis is that ATP hydrolysis by ORC is coupled to the dismantling of contacts made during pre-RC formation allowing a transition from an initiating state to an elongating state. If so, it is predicted that single-stranded DNA generated during initiation /ssDNA is known to stimulate the ORC ATPase and alter ORC conformation) alters the association of ORC with other replication factors allowing them to move away from the origin as part of the replication fork.

ssDNA at the origin during initiation triggers ORC ATP hydrolysis and a change in ORC conformation. These changes could then be coupled to restructuring of the origin associated replication machinery from a preinitiation/initiation conformation to an elongating conformation. Such a mechanism would be analogous to the changes in the associated protein complexes that occur at transcriptional promoters during the transition from initiation to the elongation (Conaway et al. 2000). If true, this mechanism would represent a robust method to ensure that the means to initiate DNA replication would not be lost until substantial ssDNA had been generated (the optimal length to stimulate the ORC ATPase is 80 bp).

These two proposed mechanisms for the roles of the ORC ATPase are not mutually exclusive. It remains possible that the ssDNA-stimulated activation of the ORC ATPase could contribute to the loading of the MCM

complex around ssDNA at the time of initiation. Indeed, the ssDNA stimulation of the ORC ATPase would be analogous to the DNA stimulation of ATP hydrolysis of the clamp loader. In both cases the formation/association with the nucleic acid target would stimulate the release and deposition of the ring shaped complex (i.e., the sliding clamp or the MCM complex).

\section{Does ORC function after pre- $R C$ recruitment?}

What is ORC's role after pre-RC assembly? Studies in replicating Xenopus extracts indicate that ORC and Cdc6p can be removed from chromatin after pre-RC formation has occurred in $\mathrm{G}_{1}$, and the remaining MCM proteins are competent to direct the initiation of DNA replication after S-phase entry (Hua et al. 1997; Rowles et al. 1999). This finding argues strongly that ORC is not required to recruit many of the components that assemble at the origin in an MCM-dependent manner. Such factors would include Cdc45p, RPA, and the eukaryotic DNA polymerases. In addition, these findings argue against a direct role in the DNA unwinding step of the initiation reaction, which is thought to occur after MCM loading and only on entry into S phase.

Despite the implied lack of function after pre-RC formation in Xenopus embryonic extracts, ORC ordinarily remains at the origin throughout the $G_{1}$ and $S$ phases of the cell cycle (Rowles et al. 1996). Given that ORC remains at the origin during initiation, what could its function be? One possibility is that ORC remains merely to act as a chromosomal landmark to identify the site of each origin in subsequent cell cycles. For example, it is possible that ORC bound to one daughter chromosome could facilitate binding of ORC to the other daughter chromosome. Indeed, because the exact number of ORC complexes bound at each origin is unknown and could be greater than one (Wilmes and Bell 2002), there is a possibility that the retention of ORC at the origin could facilitate binding of additional ORC molecules at that same site. It is also possible that the artificial means of ORC removal used in the Xenopus extract experiments (e.g., salt extraction) actually reflects the loss of ORCassociation with other replication factors at the origins that is ordinarily regulated by other means (e.g., by ATPregulated changes, see above). Finally, the retention of ORC at origins could be involved in other nonessential functions not assayed in the Xenopus replication extracts (e.g., formation of heterochromatin, see below).

\section{Regulation of ORC: subunit modification and complex remodeling}

The central role of ORC function during the initiation of replication makes it a prime target for cell cycle regulators. In S. cerevisiae, the synthesis of ORC is not highly regulated either at a transcriptional or translational level. There is evidence, however, that ScORC is phosphorylated in a cell cycle-regulated manner on both the Orc2p and Orc6p subunits. Both biochemical and genetic 
studies strongly suggest that this phosphorylation is dependent on cyclin-dependent kinases (Nguyen et al. 2001; Vas et al. 2001). Strains lacking the consensus CDK phosphorylation sites on Orc2p and Orc6p are found to replicate normally, indicating that phosphorylation of these sites is not essential for the initiation of replication. Instead, it appears that these modifications to ScORC inhibit new pre-RC formation after entry into $S$ phase. In $S$. cerevisiae, the simultaneous mutation of the CDK phosphorylation sites on ORC, elimination of the Cdc6p N-terminus (preventing its degradation), and constitutive localization of MCM proteins to the nucleus result in a strain that inappropriately reinitiates DNA replication within the same cell cycle, presumably by allowing new pre-RC formation (Nguyen et al. 2001). Similar studies of $S$. pombe ORC also suggest that phosphorylation of ORC negatively regulates reinitiation of replication (Vas et al. 2001).

The molecular consequences of ORC phosphorylation that inhibit pre-RC formation are unclear. The simplest hypothesis is that modification directly inhibits association between ORC and other components of the pre-RC. Alternatively, phosphorylation could alter an activity of ORC that is indirectly required for pre-RC formation (e.g., ATP binding) although no effect of phosphorylation on ORC's biochemical activities has been described. A better understanding of the consequences of such modifications will be obtained through the study of reconstituted assays for pre-RC formation from both Xenopus and yeast. These studies have already demonstrated that the addition of CDK activity or S phase extract inhibits new pre-RC formation (e.g., see Seki and Diffley 2000) and further dissection of these assays should provide a molecular understanding of the inhibitory mechanisms.

The regulation of ORC function in metazoans is likely to include other mechanisms in addition to phosphorylation. Unlike the relatively stable expression of ORC in yeast cells, studies of DMORC1 suggest that this subunit is limiting for DNA replication (Asano and Wharton 1999). In addition, in both mammalian and Drosophila cells ORC1 transcription is responsive to E2F1 and is regulated during the cell cycle (Ohtani et al. 1996; Asano and Wharton 1999). A second mechanism to regulate ORC function in mammalian cells may involve alteration of the association of ORC subunits. Unlike ORC from budding yeast, Drosophila, and Xenopus, the subunits of the SpORC and mammalian ORC are not always found in a stable complex (Moon et al. 1999; Natale et al. 2000; Thome et al. 2000). For example, SpOrc4p is retained on chromatin under conditions that elute the remainder of SpORC (Moon et al. 1999). Similarly, whereas mammalian Orc2p is found constitutively on the chromatin, mammalian Orclp is removed from the chromatin at the end of $S$ phase and only rebinds as cells reenter $\mathrm{G}_{1}$ (Natale et al. 2000; Tatsumi et al. 2000; Kreitz et al. 2001). The mechanisms that control the association of the ORC subunits are unclear but may include proteolysis. Recent studies suggest that HsOrcl is proteolyzed during $S$ phase as a mechanism to prevent rereplication (Kreitz et al. 2001). In contrast, other studies have found HsORClp is stable throughout the cell cycle (Saha et al. 1998; Okuno et al. 2001; Li and DePamphilis 2002). In an interesting cross section of these apparently contradictory results, a recent study has demonstrated that ORC derived from Hamster cells is stable during the cell cycle but differentially modified by a limited number of ubiquitin conjugates during the cell cycle ( $\mathrm{Li}$ and DePamphilis 2002). It is possible that the differences reflect different mechanisms of mammalian Orclp regulation in different cell lines/types.

Consistent with the existence of HsORC lacking Orclp, studies addressing the assembly of HsORC found that a core subcomplex of HsOrc2-5p was readily assembled in insect cells (Dhar et al. 2001a; Vashee et al. 2001), but that a six subunit complex was only isolated if the nuclei of the same cells are extracted with high salt (Vashee et al. 2001). Together, these findings suggest that the six subunit HsORC is only assembled on the chromatin during the $G_{1}$ and $S$ phase of the cell cycle. If true, this model suggests that a complex of HsORC lacking HsOrclp is competent for chromatin binding (unlike the situation in Drosophila and S. cerevisiae), although the specificity of this interaction is unclear.

\section{ORC: not just for replication anymore}

ORC's functions extend beyond DNA replication. As described above, not all of the ORC binding sites in the $S$. cerevisiae cells colocalize with origins of replication. Interestingly, the majority of these sites colocalize heterochromatin, including telomeres and one of the silent mating type loci $(H M L)$. In addition, ORC has been implicated in the control of $\mathrm{M}$ phase events, including chromosome condensation and integrity.

\section{ORC and the establishment of heterochromatin}

The clearest case of an alternate function for ORC is in the establishment of transcriptionally repressed domains at the $S$. cerevisiae silent mating type loci, $H M R$ and $H M L$ (for review, see Shore 2001). ORC's role in silencing was recognized early on through genetic screens that identified mutations in ScORC2 and ScORC5 as defective for mating type silencing (Foss et al. 1993; Micklem et al. 1993). The role of ORC in silencing was not surprising as all four of the mating-type silencers (HMRE, $H M R I, H M L E$, and $H M L I)$ were known to contain matches to the ACS and act as replication origins on plasmids (Dubey et al. 1991). Subsequent genetic studies demonstrated that mutants of ORC genes could be identified that distinguished between ORC's function in DNA replication and its role in transcriptional silencing (Bell et al. 1995; Fox et al. 1995; Dillin and Rine 1997). Cloning of the ORC1 gene found that it encoded a protein with substantial similarity to Sir3p, an essential factor for mating-type silencing. This similarity was particularly strong at the $\mathrm{N}$ terminus and a mutation that removes this domain results in a loss of transcriptional silencing but has no effect on DNA replication (Bell et al. 
1995). The role of this domain in mating-type silencing is to recruit Sirlp, a second key protein in the establishment of mating-type silencing (Triolo and Sternglanz 1996; Fox et al. 1997).

Although ORC clearly contains separable domains required only for silencing, it remained possible that ORC's role at the silencers also involves a DNA replication function. This hypothesis is supported by a number of different findings, including a seminal study indicating that passage through $S$ phase is required for the establishment of silencing (Miller and Nasmyth 1984) and the identification of mutations in several other DNA replication genes as defective in silencing (Axelrod and Rine 1991; Ehrenhofer-Murray et al. 1999). In addition, each of the cis-acting sequences required for mating-type silencing has the potential to act as an origin on a plasmid (Dubey et al. 1991). In contrast, other studies argue against a replicative role for ORC in silencing. For example, the mating-type silencers associated with the $H M L$ locus fail to initiate replication at their normal chromosomal position (Dubey et al. 1991). In addition, alleles of ORC have been identified that are defective in replication but not silencing (Dillin and Rine 1997). Recent studies strongly support the latter hypothesis. Using altered silencers that have replaced ORC and the ACS with Gal4p-Sirlp fusion protein and Gal4 DNA binding sites respectively, silencing could be established on episomes that lack origins and are therefore unable to replicate (Kirchmaier and Rine 2001; Li et al. 2001). Thus, neither the generation nor the passage of replication forks is required for the establishment of these silenced loci. Even under these circumstances, however, the requirement for passage through $S$ phase is retained.

A function in the establishment of transcriptionally repressed regions may be a conserved feature of ORC. Several lines of evidence support a role for DmORC in the establishment or maintenance of the Drosophila heterochromatin (Pak et al. 1997; Huang et al. 1998). First, DmORC interacts directly with HP1, a key component of Drosophila heterochromatin, and a similar interaction is also observed between XlORC and Xenopus HP1. In vitro studies localized the strongest interaction domain to the $\mathrm{N}$ terminus of DmOrclp (Pak et al. 1997), similar to the requirement of the $\mathrm{N}$ terminus of ScOrclp to interact with Sirlp. This region overlaps a bromo-adjacent homology $(\mathrm{BAH})$ domain that is found in multiple Orc1 proteins as well as Sir3p and DNA methyl-transferases, although the functional significance of this domain is unknown (Callebaut et al. 1999). Second, mutations in DmORC result in mislocalization of HP1, suggesting that, as for $S$. cerevisiae Sirlp, DmORC acts to recruit HP1 to heterochromatin. Consistent with this hypothesis, DmORC is enriched at heterochromatic regions of the Drosophila genome (Pak et al. 1997). Third, mutations in DmORC suppress heterochromatin-dependent transcriptional repression (i.e., position-effect variegation) (Pak et al. 1997).

Together these findings support the hypothesis that ORC is involved not only in the replication of chromosomes but also in the establishment and maintenance of at least a subset of chromatin domains. The reason to use ORC as opposed to any of hundreds of other DNA binding proteins is unclear. It is possible that ORC has been singled out because of its regular distribution along the chromosome (Wyrick et al. 2001). Alternatively, ORC may play a role in regulating chromatin structure that is yet to be fully appreciated. Along these lines, it has been demonstrated that ORC is responsible for positioning nucleosomes at ARS1 (Lipford and Bell 2001). In addition, HsORC interacts with the histone acetyl transferase, HBO1 (Iizuka and Stillman 1999; Burke et al. 2001). Finally, despite the fact that replication fork passage is not required for the establishment of silencing, it is possible that the tight coupling between DNA replication and chromatin assembly may have initially favored proteins associated with origins to recruit chromatin assembly factors required for heterochromatin assembly.

\section{Does ORC function in $M$ phase?}

The coupling of DNA replication to chromatid cohesion and chromatin assembly (for reviews, see Skibbens 2000; Mello and Almouzni 2001) raises the possibility that ORC could be involved in either of these events or other events that may depend on these functions. Genetic analysis of ORC mutant cells has found that these cells have defects in passage through $M$ phase. Despite this, more recent studies suggest that these phenotypes are most likely caused by secondary consequences of replication defects and not a direct involvement of ORC in these events.

Many temperature sensitive ORC mutants in S. cerevisiae arrest prior to mitosis with at least a proportion of the cells having largely completed DNA replication (Bell et al. 1993; Dillin and Rine 1998). Although it was possible that these alleles were incompletely penetrant (it is likely as few as one in five origins must be activated to replicate the $S$. cerevisiae genome), these findings also raised the possibility that a loss of ORC function prevented some event in $M$ phase. Interestingly, this arrest was still observed when the DNA replication/damage checkpoint proteins Rad9p or Mec1p were mutated (Dillin and Rine 1998), suggesting that the $G_{2}$ arrest was not caused by checkpoint pathways involving these proteins. In contrast, if the mutant cells were arrested at $M$ phase and then brought to the nonpermissive temperature and released, cells arrested with a $G_{1}$ DNA content. This suggested that ORC mutants could arrest at either $G_{2} / M$ or prior to the initiation of DNA synthesis. Similar findings have been observed in Drosophila. Flies carrying homozygous mutations of DmORC2 and DmORC5 show clear defects in DNA replication but are also defective in chromosome condensation, have an elevated levels of chromosome breakage, and an abnormally high number of cells arrested in metaphase (Loupart et al. 2000; Pflumm and Botchan 2001).

Does ORC function directly in $M$ phase? Because these experiments only assessed the final arrest point of the ORC mutations, it remained possible that the failure to complete $\mathrm{M}$ phase was attributable to defects in DNA 
replication inducing other checkpoint mechanisms rather than a direct role of ORC in mitosis. Consistent with this hypothesis, determination of the cell cycle execution point of ScORC using multiple ORC mutations identified a narrow window spanning late $G_{1}$ phase through early $S$ phase during which ORC is required for normal cell cycle progression (O. Aparicio and S.P. Bell, unpubl.). Because the alleles tested are known to eliminate ORC DNA binding (Aparicio et al. 1997), this finding strongly suggests that there is no requirement for chromatin bound ORC from early $S$ phase to the completion of $M$ phase for cell cycle progression. Similarly, immunofluorescence studies of XlORC in $X$. laevis tissue culture cells suggest that ORC is removed from the chromatin during $M$ phase (Romanowski et al. 1996).

What is responsible for the $G_{2} / M$ arrest observed in ScORC subunit mutations? Further studies of these alleles suggest that they activate the spindle assembly checkpoint leading to the $\mathrm{G}_{2} / \mathrm{M}$ arrest $(\mathrm{O}$. Aparicio, unpubl.). Although the mechanism for the activation of the checkpoint remains unclear, it is likely that incomplete replication of the chromosomes results in defects in spindle assembly. Interestingly, mutation of Cdc13p, a protein involved in the duplication of telomeres, also results in the activation of the spindle assembly checkpoint (Wang et al. 2000).

It is likely that the mitotic defects observed in DmORC mutations are also the indirect result of DNA replication defects. The phenotypes of the Drosophila ORC mutations are similar to those of other mutations in DNA replication proteins including mutant alleles of DmMCM4 and DmPCNA (Pflumm and Botchan 2001). In addition, sites of altered chromosome condensation appear to correlate with sites that exhibit altered replication timing in embryos mutant for DmORC2. Thus, in both $S$. cerevisiae and Drosophila, a general defect in DNA replication may have consequences for the correct preparation of chromosomes for the subsequent mitosis. Although it is unclear how these alterations in DNA replication lead to defects in chromosome condensation, these findings suggest that there are important events that must be coordinated between DNA replication and mitosis.

Studies of the localization of the Orc6 in Drosophila and human cells suggest a more direct connection between ORC and other events of the cell cycle. Studies in Drosophila cells indicate that there is a substantial excess of DmOrc6p relative to the other DmORC subunits. This protein is primarily in the cytoplasm and is particularly concentrated at the cell membrane (Chesnokov et al. 2001). Interestingly, observation of DmOrc6 localization during the end of mitosis indicates that it is concentrated at the cytokinetic furrow (I. Chesnokov and $\mathrm{M}$. Botchan, unpubl.). In human cells, HsOrc6p also appears to be localized at the cytokinetic furrow as well as at the kinetochore (B. Stillman, unpubl.). Although the exact function of this localization remains to be determined, it is intriguing to speculate that metazoan Orc6p is involved in a feedback mechanism prevent- ing ORC function or pre-RC formation until mitosis is completed.

\section{Conclusions}

The identification of ORC has led the way in the characterization of the proteins that assemble at origins during the cell cycle. By studying these assembly events, many of the key mechanisms controlling DNA replication during the cell cycle have been determined. Despite a detailed knowledge of the order and timing of replication factor association with the origin, our understanding of the biochemical function performed by these factors remains primitive for the majority of the initiation factors, and ORC is no exception. Although it is clear that ORC associates with specific regions of the genome, the mechanism by which it arrives at these sites remains obscure, particularly in metazoans. Similarly, the role of ORC in the formation of the pre-RC and the control of ORC activity by ATP binding and hydrolysis remain to be determined. Both new biochemical assays and additional structural studies of ORC will be essential to advance our understanding of this critical complex.

The function of ORC outside of DNA replication represents just one of an increasing number of connections between different regulators of chromosome propagation. For example, recent studies indicate that correct sister chromatid cohesion influences DNA repair and recombination (Sjogren and Nasmyth 2001; Watanabe et al. 2001). The detection of ORC mutations by the spindle checkpoint suggests that there is coordination between DNA replication and the preparation of chromosomes for segregation that remains to be understood. Similarly, although the role of Orc6 at the cytokinetic furrow is unclear, such observations are likely to lead to unanticipated molecular connections. Indeed, as the events that control chromosome duplication and segregation are understood in mechanistic detail, it will become increasingly important to investigate how these events are coordinated with one another. The ability to identify the genome-wide location of the factors that control chromosome duplication and segregation will provide information about the chromosomal landscape and insights into the connections between them.

\section{Acknowledgments}

I would like to thank Mike Botchan, Bruce Stillman, and Oscar Aparicio for communicating unpublished data and Angelika Amon, Anindya Dutta, Oscar Aparicio, Milan deVries, Gwen Wilmes, and Robyn Tanny for helpful comments on the manuscript. Work in S.P.B.'s laboratory is supported by the Howard Hughes Medical Institute and the National Institutes of Health (GM-52339 and GM-58701). S.P.B. is an employee of the Howard Hughes Medical Institute.

\section{References}

Adachi, Y., Usukura, J., and Yanagida, M. 1997. A globular complex formation by $\mathrm{Ndal}$ and the other five members of the 
MCM protein family in fission yeast. Genes Cells 2: 467479.

Aparicio, O.M., Weinstein, D.M., and Bell, S.P. 1997. Components and dynamics of DNA replication complexes in S. cerevisiae: Redistribution of MCM proteins and Cdc45p during S phase. Cell 91: 59-69.

Asano, M. and Wharton, R.P. 1999. E2F mediates developmental and cell cycle regulation of ORC1 in Drosophila. EMBO J. 18: $2435-2448$.

Austin, R.J., Orr-Weaver, T.L., and Bell, S.P. 1999. Drosophila ORC specifically binds to ACE3, an origin of DNA replication control element. Genes \& Dev. 13: 2639-2649.

Axelrod, A. and Rine, J. 1991. A role for CDC7 in repression of transcription at the silent mating-type locus HMR in Saccharomyces cerevisiae. Mol. Cell. Biol. 11: 1080-1091.

Bell, S.P. 1995. Eukaryotic replicators and associated protein complexes. Curr. Opin. Genet. Dev. 5: 162-167.

Bell, S.P. and Stillman, B. 1992. ATP-dependent recognition of eukaryotic origins of DNA replication by a multiprotein complex. Nature 357: 128-134.

Bell, S.P. and Dutta, A. 2002. DNA replication in eukaryotic cells. Annu. Rev. Biochem. (in press).

Bell, S.P., Kobayashi, R., and Stillman, B. 1993. Yeast origin recognition complex functions in transcription silencing and DNA replication. Science 262: 1844-1849.

Bell, S.P., Mitchell, J., Leber, J., Kobayashi, R., and Stillman, B. 1995. The multidomain structure of Orclp reveals similarity to regulators of DNA replication and transcriptional silencing. Cell 83: 563-568.

Bielinsky, A.K. and Gerbi, S.A. 2001. Where it all starts: Eukaryotic origins of DNA replication. J. Cell. Sci. 114: 643651.

Bielinsky, A., Blitzblau, H., Beall, E.L., Ezrokhi, M., Smith, H.S., Botchan, M.R., and Gerbi, S.A. 2001. Origin recognition complex binding to a metazoan replication origin. Curr. Biol. 11: $1427-1431$.

Blat, Y. and Kleckner, N. 1999. Cohesins bind to preferential sites along yeast chromosome III, with differential regulation along arms versus the centric region. Cell 98: 249-259.

Blow, J.J., Gillespie, P.J., Francis, D., and Jackson, D.A. 2001. Replication origins in Xenopus egg extract are 5-15 kilobases apart and are activated in clusters that fire at different times. I. Cell Biol. 152: 15-25.

Blumenthal, A.B., Kriegstein, H.J., and Hogness, D.S. 1974. The units of DNA replication in Drosophila melanogaster chromosomes. Cold Spring Harb. Symp. Quant. Biol. 38: 205223

Bosco, G., Du, W., and Orr-Weaver, T.L. 2001. DNA replication control through interaction of E2F-RB and the origin recognition complex. Nat. Cell. Biol. 3: 289-295.

Brewer, B.J. 1994. Intergenic DNA and the sequence requirements for replication initiation in eukaryotes. Curr. Opin. Genet. Dev. 4: 196-202.

Burke, T.W., Cook, J.G., Asano, M., and Nevins, J.R. 2001. Replication factors MCM2 and ORC1 interact with the histone acetyltransferase HBO1. J. Biol. Chem. 276: 15397-15408.

Callebaut, I., Courvalin, J.C., and Mornon, J.P. 1999. The BAH (bromo-adjacent homology) domain: A link between DNA methylation, replication, and transcriptional regulation. FEBS Lett. 446: 189-193.

Carpenter, P.B., Mueller, P.R., and Dunphy, W.G. 1996. Role for a Xenopus Orc2-related protein in controlling DNA replication. Nature 379: 357-360.

Chaudhuri, B., Xu, H., Todorov, I., Dutta, A., and Yates, J.L. 2001. Human DNA replication initiation factors, ORC and MCM, associate with oriP of Epstein-Barr virus. Proc. Nat1.
Acad. Sci. 98: 10085-10089.

Chesnokov, I., Gossen, M., Remus, D., and Botchan, M. 1999. Assembly of functionally active Drosophila origin recognition complex from recombinant proteins. Genes \& Dev. 13: $1289-1296$.

Chesnokov, I., Remus, D., and Botchan, M. 2001. Functional analysis of mutant and wild-type Drosophila origin recognition complex. Proc. Natl. Acad. Sci. 98: 11997-12002.

Chuang, R.Y. and Kelly, T.J. 1999. The fission yeast homologue of Orc4p binds to replication origin DNA via multiple AThooks. Proc. Natl. Acad. Sci. 96: 2656-2661.

Conaway, J.W., Shilatifard, A., Dvir, A., and Conaway, R.C. 2000. Control of elongation by RNA polymerase II. Trends Biochem. Sci. 25: 375-380.

Coverley, D. and Laskey, R.A. 1994. Regulation of eukaryotic DNA replication. Annu. Rev. Biochem. 63: 745-776.

Dhar, S.K., Delmolino, L., and Dutta, A. 2001a. Architecture of the human origin recognition complex. J. Biol. Chem. 276: 29067-29071

Dhar, S.K., Yoshida, K., Machida, Y., Khaira, P., Chaudhuri, B. Wohlschlegel, J.A., Leffak, M., Yates, J., and Dutta, A. 2001b. Replication from oriP of Epstein-Barr virus requires human ORC and is inhibited by geminin. Cell 106: 287-296.

Diffley, J.F., Cocker, J.H., Dowell, S.J., and Rowley, A. 1994. Two steps in the assembly of complexes at yeast replication origins in vivo. Cell 78: 303-316.

Dillin, A. and Rine, J. 1997. Separable functions of ORC5 in replication initiation and silencing in Saccharomyces cerevisiae. Genetics 147: 1053-1062.

. 1998. Roles for ORC in M phase and S phase. Science 279: $1733-1737$

Dowell, S.J., Romanowski, P., and Diffley, J.F. 1994. Interaction of Dbf4, the Cdc7 protein kinase regulatory subunit, with yeast replication origins in vivo. Science 265: 1243-1246.

Dubey, D.D., Davis, L.R., Greenfeder, S.A., Ong, L.Y., Zhu, J.G., Broach, J.R., Newlon, C.S., and Huberman, J.A. 1991. Evidence suggesting that the ARS elements associated with silencers of the yeast mating-type locus HML do not function as chromosomal DNA replication origins. Mol. Cell. Biol. 11: 5346-5355.

Dutta, A. and Bell, S.P. 1997. Initiation of DNA replication in eukaryotic cells. In Annual reviews of cell and developmental biology, pp. 293-332.

Ehrenhofer-Murray, A.E., Kamakaka, R.T., and Rine, J. 1999. A role for the replication proteins PCNA, RF-C, polymerase epsilon and Cdc45 in transcriptional silencing in Saccharomyces cerevisiae. Genetics 153: 1171-1182.

Ellison, V. and Stillman, B. 2001. Opening of the clamp: An intimate view of an ATP-driven biological machine. Cell 106: 655-660.

Foss, M., McNally, F.J., Laurenson, P., and Rine, J. 1993. Origin recognition complex (ORC) in transcriptional silencing and DNA replication in S. cerevisiae. Science 262: 1838-1844.

Fox, C.A., Loo, S., Dillin, A., and Rine, J. 1995. The origin recognition complex has essential functions in transcriptional silencing and chromosomal replication. Genes \& Dev. 9: 911-924.

Fox, C.A., Ehrenhofer-Murray, A.E., Loo, S., and Rine, J. 1997. The origin recognition complex, SIR 1 , and the $S$ phase requirement for silencing. Science 276: 1547-1551.

Geraghty, D.S., Ding, M., Heintz, N.H., and Pederson, D.S. 2000. Premature structural changes at replication origins in a yeast minichromosome maintenance (MCM) mutant. $I$. Biol. Chem. 275: 18011-18021.

Gilbert, D.M. 2001. Making sense of eukaryotic DNA replication origins. Science 294: 96-100. 
Grallert, B. and Nurse, P. 1996. The ORC1 homolog orp1 in fission yeast plays a key role in regulating onset of $S$ phase. Genes \& Dev. 10: 2644-2654.

Hua, X.H. and Newport, J. 1998. Identification of a preinitiation step in DNA replication that is independent of origin recognition complex and cdc6, but dependent on cdk2. J. Cell Biol. 140: 271-281.

Hua, X.H., Yan, H., and Newport, J. 1997. A role for Cdk2 kinase in negatively regulating DNA replication during $S$ phase of the cell cycle. J. Cell Biol. 137: 183-192.

Huang, D.W., Fanti, L., Pak, D.T., Botchan, M.R., Pimpinelli, S., and Kellum, R. 1998. Distinct cytoplasmic and nuclear fractions of Drosophila heterochromatin protein 1: Their phosphorylation levels and associations with origin recognition complex proteins. J. Cell Biol. 142: 307-318.

Hyrien, O., Maric, C., and Mechali, M. 1995. Transition in specification of embryonic metazoan DNA replication origins. Science 270: 994-997.

Iizuka, M. and Stillman, B. 1999. Histone acetyltransferase HBO1 interacts with the ORC1 subunit of the human initiator protein. I. Biol. Chem. 274: 23027-23034.

Jacob, F., Brenner, S., and Cuzin, F. 1963. On the regulation of DNA replication in bacteria. Cold Spring Harbor Symp. Quant. Biol. 28: 329-348.

Kirchmaier, A.L. and Rine, J. 2001. DNA replication-independent silencing in S. cerevisiae. Science 291: 646-650.

Klemm, R.D. and Bell, S.P. 2001. ATP bound to the origin recognition complex is important for preRC formation. Proc. Nat1. Acad. Sci. 98: 8361-8367.

Klemm, R.D., Austin, R.J., and Bell, S.P. 1997. Coordinate binding of ATP and origin DNA regulates the ATPase activity of the origin recognition complex. Cell 88: 493-502.

Kong, D. and DePamphilis, M.L. 2001. Site-specific DNA binding of the Schizosaccharomyces pombe origin recognition complex is determined by the Orc4 subunit. Mol. Cell. Biol. 21: 8095-8103.

Kreitz, S., Ritzi, M., Baack, M., and Knippers, R. 2001. The human origin recognition complex protein 1 dissociates from chromatin during S phase in HeLa cells. J. Biol. Chem. 276: 6337-6342.

Labib, K. and Diffley, J.F. 2001. Is the MCM2-7 complex the eukaryotic DNA replication fork helicase? Curr. Opin. Genet. Dev. 11: 64-70.

Laloraya, S., Guacci, V., and Koshland, D. 2000. Chromosomal addresses of the cohesin component Mcdlp. I. Cell Biol. 151: $1047-1056$

Landis, G., Kelley, R., Spradling, A.C., and Tower, J. 1997. The $\mathrm{k} 43$ gene, required for chorion gene amplification and diploid cell chromosome replication, encodes the Drosophila homolog of yeast origin recognition complex subunit 2. Proc. Nat1. Acad. Sci. 94: 3888-3892.

Lee, D. and Bell, S.P. 1997. Architecture of the yeast origin recognition complex bound to origins of DNA replication. Mol. Cell. Biol. 17: 7159-7168.

Lee, D.G., Makhov, A.M., Klemm, R.D., Griffith, J.D., and Bell, S.P. 2000. Regulation of origin recognition complex conformation and ATPase activity: Differential effects of singlestranded and double-stranded DNA binding. EMBO $J$. 19: 4774-4782.

Lee, J.K., Moon, K.Y., Jiang, Y., and Hurwitz, J. 2001. The Schizosaccharomyces pombe origin recognition complex interacts with multiple AT-rich regions of the replication origin DNA by means of the AT-hook domains of the spOrc4 protein. Proc. Natl. Acad. Sci. 98: 13589-13594.

Li, C.J. and DePamphilis, M.L. 2002. Mammalian Orc1 protein is selectively released from chromatin and ubiquitinated during the S-to-M transition in the cell division cycle. Mol. Cell. Biol. 22: 105-116.

Li, J.J. and Herskowitz, I. 1993. Isolation of ORC6, a component of the yeast origin recognition complex by a one-hybrid system. Science 262: 1870-1874.

Li, Y.C., Cheng, T.H., and Gartenberg, M.R. 2001. Establishment of transcriptional silencing in the absence of DNA replication. Science 291: 650-653.

Liang, C. and Stillman, B. 1997. Persistent initiation of DNA replication and chromatin-bound MCM proteins during the cell cycle in cdc6 mutants. Genes \& Dev. 11: 3375-3386.

Liang, C., Weinreich, M., and Stillman, B. 1995. ORC and Cdc6p interact and determine the frequency of initiation of DNA replication in the genome. Cell 81: 667-676.

Lipford, J.R. and Bell, S.P. 2001. Nucleosomes positioned by ORC facilitate the initiation of DNA replication. Mol. Cell 7: 21-30.

Liu, J., Smith, C.L., DeRyckere, D., DeAngelis, K., Martin, G.S. and Berger, J.M. 2000. Structure and function of Cdc6/ Cdc18: Implications for origin recognition and checkpoint control. Mol. Cell 6: 637-648.

Loupart, M.L., Krause, S.A., and Heck, M.S. 2000. Aberrant replication timing induces defective chromosome condensation in Drosophila ORC2 mutants. Curr. Biol. 10: 1547-1556.

Maiorano, D., Moreau, J., and Mechali, M. 2000. XCDT1 is required for the assembly of pre-replicative complexes in Xenopus laevis. Nature 404: 622-625.

Mello, J.A. and Almouzni, G. 2001. The ins and outs of nucleosome assembly. Curr. Opin. Genet. Dev. 11: 136-141.

Micklem, G., Rowley, A., Harwood, J., Nasmyth, K., and Diffley, J.F. 1993. Yeast origin recognition complex is involved in DNA replication and transcriptional silencing. Nature 366: 87-89.

Miller, A.M. and Nasmyth, K.A. 1984. Role of DNA replication in the repression of silent mating type loci in yeast. Nature 312: 247-251.

Mizushima, T., Takahashi, N., and Stillman, B. 2000. Cdc6p modulates the structure and DNA binding activity of the origin recognition complex in vitro. Genes \& Dev. 14: 16311641.

Moon, K.Y., Kong, D., Lee, J.K., Raychaudhuri, S., and Hurwitz, J. 1999. Identification and reconstitution of the origin recognition complex from Schizosaccharomyces pombe. Proc. Nat1. Acad. Sci. 96: 12367-12372.

Muzi-Falconi, M. and Kelly, T.J. 1995. Orp1, a member of the Cdc18/Cdc6 family of S-phase regulators, is homologous to a component of the origin recognition complex. Proc. Natl. Acad. Sci. 92: 12475-12479.

Natale, D.A., Li, C.J., Sun, W.H., and DePamphilis, M.L. 2000. Selective instability of Orcl protein accounts for the absence of functional origin recognition complexes during the M-G(1) transition in mammals. EMBO J. 19: 2728-2738.

Newlon, C.S. and Theis, J.F. 1993. The structure and function of yeast ARS elements. Curr. Opin. Genet. Dev. 3: 752-758.

Nguyen, V.Q., Co, C., and Li, J.J. 2001. Cyclin-dependent kinases prevent DNA re-replication through multiple mechanisms. Nature 411: 1068-1073.

Nishitani, H., Lygerou, Z., Nishimoto, T., and Nurse, P. 2000. The Cdt1 protein is required to license DNA for replication in fission yeast. Nature 404: 625-628.

O'Donnell, M. and Hingorani, M.M. 2000. A tale of toroids in DNA metabolism. Nat. Rev. Mol. Cell. Biol. 1: 22-30.

Ogawa, Y., Takahashi, T., and Masukata, H. 1999. Association of fission yeast Orp1 and Mcm6 proteins with chromosomal replication origins. Mol. Cell. Biol. 19: 7228-7236.

Ohtani, K., DeGregori, J., Leone, G., Herendeen, D.R., Kelly, 
T.J., and Nevins, J.R. 1996. Expression of the HsOrcl gene, a human ORC1 homolog, is regulated by cell proliferation via the E2F transcription factor. Mol. Cell. Biol. 16: 6977-6984.

Okuno, Y., McNairn, A.J., den Elzen, N., Pines, J., and Gilbert, D.M. 2001. Stability, chromatin association, and functional activity of mammalian pre-replication complex proteins during the cell cycle. EMBO J. 20: 4263-4277.

Pak, D.T., Pflumm, M., Chesnokov, I., Huang, D.W., Kellum, R., Marr, J., Romanowski, P., and Botchan, M.R. 1997. Association of the origin recognition complex with heterochromatin and HP1 in higher eukaryotes. Cell 91: 311-323.

Pasero, P., Duncker, B.P., Schwob, E., and Gasser, S.M. 1999. A role for the Cdc7 kinase regulatory subunit Dbf4p in the formation of initiation-competent origins of replication. Genes \& Dev. 13: 2159-2176.

Perkins, G. and Diffley, J.F. 1998. Nucleotide-dependent prereplicative complex assembly by Cdc6p, a homolog of eukaryotic and prokaryotic clamp-loaders. Mol. Cell 2: 23-32.

Pflumm, M.F. and Botchan, M.R. 2001. Orc mutants arrest in metaphase with abnormally condensed chromosomes. Development 128: 1697-1707.

Pinto, S., Quintana, D.G., Smith, P., Mihalek, R.M., Hou, Z.H., Boynton, S., Jones, C.J., Hendricks, M., Velinzon, K., Wohlschlegel, J.A., et al. 1999. latheo encodes a subunit of the origin recognition complex and disrupts neuronal proliferation and adult olfactory memory when mutant. Neuron 23: 45-54.

Raghuraman, M.K., Winzeler, E.A., Collingwood, D., Hunt, S., Wodicka, L., Conway, A., Lockhart, D.J., Davis, R.W., Brewer, B.J., and Fangman, W.L. 2001. Replication dynamics of the yeast genome. Science 294: 115-121.

Rao, H. and Stillman, B. 1995. The origin recognition complex interacts with a bipartite DNA binding site within yeast replicators. Proc. Natl. Acad. Sci. 92: 2224-2228.

Reeves, R. and Beckerbauer, L. 2001. HMGI/Y proteins: Flexible regulators of transcription and chromatin structure. Biochim. Biophys. Acta. 1519: 13-29.

Romanowski, P., Madine, M.A., Rowles, A., Blow, J.J., and Laskey, R.A. 1996. The Xenopus origin recognition complex is essential for DNA replication and MCM binding to chromatin. Curr. Biol. 6: 1416-1425.

Rowles, A., Chong, J.P., Brown, L., Howell, M., Evan, G.I., and Blow, J.J. 1996. Interaction between the origin recognition complex and the replication licensing system in Xenopus. Cell 87: 287-296.

Rowles, A., Tada, S., and Blow, J.J. 1999. Changes in association of the Xenopus origin recognition complex with chromatin on licensing of replication origins. J. Cell. Sci. 112: 20112018.

Rowley, A., Cocker, J.H., Harwood, J., and Diffley, J.F. 1995. Initiation complex assembly at budding yeast replication origins begins with the recognition of a bipartite sequence by limiting amounts of the initiator, ORC. EMBO I. 14: 26312641.

Royzman, I., Austin, R.J., Bosco, G., Bell, S.P., and Orr-Weaver, T.L. 1999. ORC localization in Drosophila follicle cells and the effects of mutations in dE2F and dDP. Genes \& Dev. 13: $827-840$.

Saha, P., Chen, J., Thome, K.C., Lawlis, S.J., Hou, Z.H., Hendricks, M., Parvin, J.D., and Dutta, A. 1998. Human CDC6/ Cdc18 associates with Orc1 and cyclin-cdk and is selectively eliminated from the nucleus at the onset of S phase. Mol. Cell. Biol. 18: 2758-2767.

Santocanale, C. and Diffley, J.F. 1996. ORC- and Cdc6-dependent complexes at active and inactive chromosomal replication origins in Saccharomyces cerevisiae. EMBO J. 15: 6671-
6679.

Sasaki, T., Sawado, T., Yamaguchi, M., and Shinomiya, T. 1999. Specification of regions of DNA replication initiation during embryogenesis in the 65-kilobase DNApol $\alpha$-dE2F locus of Drosophila melanogaster. Mol. Cell. Biol. 19: 547-555.

Schepers, A., Ritzi, M., Bousset, K., Kremmer, E., Yates, J.L., Harwood, J., Diffley, J.F., and Hammerschmidt, W. 2001. Human origin recognition complex binds to the region of the latent origin of DNA replication of Epstein-Barr virus. EMBO J. 20: 4588-4602.

Seki, T. and Diffley, J.F. 2000. Stepwise assembly of initiation proteins at budding yeast replication origins in vitro. Proc. Nat1. Acad. Sci. 97: 14115-14120.

Shore, D. 2001. Transcriptional silencing: Replication redux. Curr. Biol. 11: R816-R819.

Simpson, R.T. 1990. Nucleosome positioning can affect the function of a cis-acting DNA element in vivo. Nature 343: 387-389.

Sjogren, C. and Nasmyth, K. 2001. Sister chromatid cohesion is required for postreplicative double-strand break repair in Saccharomyces cerevisiae. Curr. Biol. 11: 991-995.

Skibbens, R.V. 2000. Holding your own: Establishing sister chromatid cohesion. Genome Res. 10: 1664-1671.

Tanaka, T., Knapp, D., and Nasmyth, K. 1997. Loading of an $\mathrm{Mcm}$ protein onto DNA replication origins is regulated by Cdc6p and CDKs. Cell 90: 649-660.

Tatsumi, Y., Tsurimoto, T., Shirahige, K., Yoshikawa, H., and Obuse, C. 2000. Association of human origin recognition complex 1 with chromatin DNA and nuclease-resistant nuclear structures. J. Biol. Chem. 275: 5904-5910.

Thome, K.C., Dhar, S.K., Quintana, D.G., Delmolino, L., Shahsafaei, A., and Dutta, A. 2000. Subsets of human origin recognition complex (ORC) subunits are expressed in non-proliferating cells and associate with non-ORC proteins. J. Biol. Chem. 275: 35233-35241.

Triolo, T. and Sternglanz, R. 1996. Role of interactions between the origin recognition complex and SIR1 in transcriptional silencing. Nature 381: 251-253.

Vas, A., Mok, W., and Leatherwood, J. 2001. Control of DNA rereplication via Cdc2 phosphorylation sites in the origin recognition complex. Mol. Cell. Biol. 21: 5767-5777.

Vashee, S., Simancek, P., Challberg, M.D., and Kelly, T.J. 2001. Assembly of the human origin recognition complex. J. Biol. Chem. 276: 26666-26673.

Walter, J. and Newport, J. 2000. Initiation of eukaryotic DNA replication: Origin unwinding and sequential chromatin association of Cdc45, RPA, and DNA polymerase alpha. Mol. Cell 5: 617-627.

Wang, Y., Hu, F., and Elledge, S.J. 2000. The Bfa1/Bub2 GAP complex comprises a universal checkpoint required to prevent mitotic exit. Curr. Biol. 10: 1379-1382.

Watanabe, Y., Yokobayashi, S., Yamamoto, M., and Nurse, P. 2001. Pre-meiotic S phase is linked to reductional chromosome segregation and recombination. Nature 409: 359-363.

Wilmes, G.M. and Bell, S.P. 2002. The B2 element of the Saccharomyces cerevisiae ARS1 origin of replication requires specific sequences to facilitate pre-RC formation. Proc. Nat1. Acad. Sci. 99: 101-106.

Wyrick, J.J., Aparicio, J.G., Chen, T., Barnett, J.D., Jennings, E.G., Young, R.A., Bell, S.P., and Aparicio, O.M. 2001. Genome-wide distribution of ORC and MCM proteins in $S$. cerevisiae: High-resolution mapping of replication origins. Science 294: 2357-2360. 


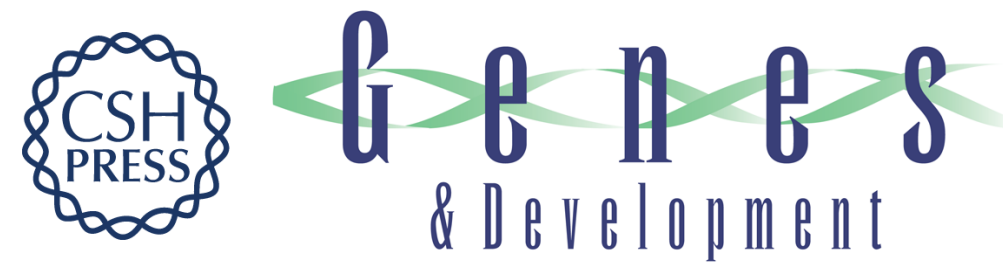

\title{
The origin recognition complex: from simple origins to complex functions
}

\author{
Stephen P. Bell
}

Genes Dev. 2002, 16:

Access the most recent version at doi:10.1101/gad.969602

$\begin{array}{ll}\text { References } & \text { This article cites } 113 \text { articles, } 67 \text { of which can be accessed free at: } \\ \text { http://genesdev.cshlp.org/content/16/6/659.full.html\#ref-list-1 }\end{array}$

License

Email Alerting Receive free email alerts when new articles cite this article - sign up in the box at the top Service right corner of the article or click here.

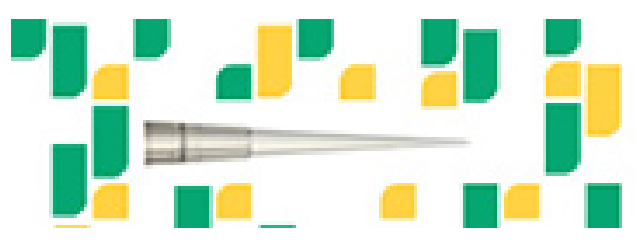

Focused on your science. 